\title{
An assessment of nutritional status of children aged 0-14 years in a slum area of Kolkata
}

\section{Sudarsan Mandal, Ram Prabhakar V, Jayita Pal,}

R. Parthasarathi, Rahul Biswas

Department of Preventive and Social Medicine, All India Institute of Hygiene and Public Health,

Kolkata, West Bengal, India

Address for the Correspondence:

Dr. Ram Prabhakar V All India Institute of Hygiene and Public Health, 110, Chittaranjan

Avenue, Kolkata - 700073

West Bengal, India.

E-mail: ramprabhakarmbbs@ gmail.com

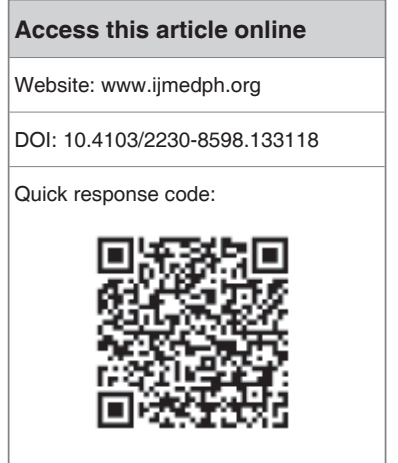

Introduction: Under-nutrition contributes to more than one-third of all deaths in children. It does this by diminishing children's immunity and making illness more dangerous. The primary aim of the study is to assess the nutritional status of children aged from 0 to 14 years in a slum area of Kolkata and secondary aim is to determine the prevalence of under-nutrition and its association with various risk factors among the study population. Materials and Methods: Community-based cross-sectional analytical study was carried out in urban slum of Chetla, Kolkata involving children of age group (0-14 years) from February to May 2012. All children (120) were examined clinically; their anthropometric measurements such as weight, height, mid upper arm circumference (MUAC) were taken using the standard operating procedures, after obtaining verbal consent from their parents with the help of a predesigned and pre-tested schedule. The anthropometric data was analyzed using World Health Organization Anthro and Anthro Plus Softwares. Results: The overall prevalence of under-nutrition among the study population was found to be $54(45 \%)$. Among infants $9(25 \%)$ were underweight, $3(8.3 \%)$ were stunted, $22(61.1 \%)$ were wasted and $23(63.9 \%)$ showed thinness. Among 1-5 years aged children, 18 $(30.5 \%)$ were underweight, $17(28.8 \%)$ were stunted, $17(28.8 \%)$ were wasted, $12(20.3 \%)$ had MUAC $12.5-13.5 \mathrm{~cm}$ and $17(28.8 \%)$ showed thinness. Among $5-14$ years aged children, 11 (44\%) were underweight, 10 (40\%) were stunted and $12(48 \%)$ showed thinness. Conclusion: The nutritional status of children in Chetla slum is not satisfactory in spite of proper immunization coverage and institutional deliveries. Special emphasis should be given for promotion of nutritional education to the mothers.

Key words: Anthropometry, Chetla, stunting, thinness, underweight, wasting

\section{INTRODUCTION}

The World Bank estimates that India is ranked $2^{\text {nd }}$ in the world of the number of children suffering from malnutrition, where $47 \%$ of the children exhibit a degree of malnutrition. ${ }^{[1]}$ The prevalence of underweight children in India is among the highest in the world and is nearly double that of SubSaharan Africa with dire consequences for mobility, mortality, productivity and economic growth. ${ }^{[2]}$ Under-nutrition contributes to more than one-third of all deaths in children. It does this by diminishing children's immunity and making illness more dangerous. An undernourished child struggles to withstand an attack of pneumonia, diarrhea or any other illness. Under-nutrition is caused by poor feeding, care and also aggravated by illness. Nutritional deprivation makes children tired and weak and lowers their intelligent quotients, thereby leading to their poor performances in school. The cycle of under-nutrition and poverty repeats itself, generation after generation. Exclusive breastfeeding for the first 6 months and continued breastfeeding together with appropriate foods can have a major impact on children's survival, growth and development. ${ }^{[1,10]}$

Under-nutrition in children can manifest itself in several ways and it is most commonly assessed through the measurement of weight and height. A child can be too short for his or her age (stunted), can have low weight for his or her height (wasted), or can have low weight for his or her age (underweight). A child who is underweight can also be stunted or wasted or both. ${ }^{[16]}$

World-wide, under-nutrition affects one in three people and each of its major forms lead to most other diseases globally based on the World Health Organization (WHO) 2000 report. Under-nutrition affects 
all age groups, but it is especially common among the poor and those with inadequate access to health education and to clean water and good sanitation. More than $70 \%$ of children with protein-energy malnutrition live in Asia, 26\% live in Africa and 4\% in Latin America and the Caribbean (WHO 2000). South Asia has the highest rates and by far the largest number of malnourished children in the world. ${ }^{[1]}$

According to WHO, the estimated numbers (in million) of underweight, stunted and wasted preschool children in 2015 in Asia is around 60, 84 and 39 million respectively.

In India alone there are approximately 60 million children who are underweight $\mathrm{t}^{[3]}$ and the prevalence is higher in rural areas compared with urban areas. ${ }^{[4]}$ However, as per National Family Health Survey (NFHS) III data, under-five mortality rate in the slum area was higher (72.7) than urban average (51.9).

According to NFHS-3, among the under-five children, about $43.1 \%$ males and $43.9 \%$ females are underweight, about $47.9 \%$ males and $48 \%$ females are stunted, about $20.7 \%$ males and $19.3 \%$ females are wasted. ${ }^{[5]}$

In West Bengal, about 39\% were underweight, 45\% were stunted and $17 \%$ were wasted among the under-five children. ${ }^{[5]}$ Although numerous studies ${ }^{[11-15,17-20]}$ were done to find out the prevalence of under-nutrition among under-five children, there were only limited studies conducted among the rest of the age group (5-14 years) in children. This study was aimed at finding out the prevalence of under-nutrition and determining its associates among children aged from 0 to 14 years in a slum of Kolkata, West Bengal.

\section{MATERIALS AND METHODS}

Community-based cross-sectional study was carried out in urban slum of Chetla, Kolkata involving children of age group (0-14 years) from $15^{\text {th }}$ February to $14^{\text {th }}$ May 2012. The sample size required was 120 considering the prevalence of under-nutrition in a slum area of Kolkata $=61 \%,{ }^{[6]}$ allowable relative error $=15 \%$. There were three units in the service area under Urban Health Centre, Chetla of All India Institute of Hygiene and Public Health (AIIH and PH), Kolkata. Each service unit consists of two sectors. Population was stratified at the level of the sector and from each sector; samples were collected randomly according to proportion to its population size. Thus, a total of 120 samples were collected. All the children were examined clinically; their anthropometric measurements such as weight, height, mid upper arm circumference (MUAC) were taken using the standard operating procedures, after obtaining verbal consent from their parents with the help of a predesigned and pretested schedule. Institutional ethical committee of $\mathrm{AIIH}$ and $\mathrm{PH}$ reviewed the proposal for ethical consideration and approval was obtained prior to the study.

The data included were weight, recumbent length (for children less than 24 months of age), height (for children more than 24 months of age) and MUAC (for children 1-5 years of age). Weight was measured to the nearest $0.1 \mathrm{~kg}$ in a Salter weighing machine and standard weighing (bathroom) scale. Height was measured against a non-stretchable tape fixed to a vertical wall, with the participant standing on a firm/level surface and it was measured to the nearest $0.1 \mathrm{~cm}$. Recumbent length (for children less than 24 months of age) was measured by using an infantometer. Each measurement was done twice and the mean of the two readings was recorded.

Socio-economic status was determined by using Modified Prasad's scale (modified for 2012). Anthropometric data was analyzed using WHO Anthro ${ }^{[7]}$ for personal computers, version 3.2.2, 2011 Software (for children aged 0-59 months) and WHO Anthro Plus ${ }^{[8]}$ version 1.0.4, 2007 Software (for children aged 5-14 years) for assessing growth and development of the children.

The definitions used for the study were as follows:

1. Wasting (acute malnutrition) is defined as the weight for height $Z$-score (WHZ) of $<-2$ standard deviation (SD). Severe wasting is considered if WHZ is $<-3 \mathrm{SD}$ or if MUAC $<11.5 \mathrm{~cm}$.

2. Stunting (chronic malnutrition) is defined as a height for age $Z$-score (HAZ) of $<-2 S D$. Severe stunting is considered if HAZ is $<-3 S D$.

3. Underweight (mixed acute and chronic malnutrition) is defined as weight for age $Z$-score (WAZ) of $<-2 S D$. Severe underweight is considered if WAZ is $<-3 \mathrm{SD}$.

4. Thinness (measure of body fat) is defined as a body mass index for $Z$-score (BMIZ) of $<-2 \mathrm{SD}$. Severe thinness was considered if BMIZ was $<-3 \mathrm{SD}$.

In case of non-response of mother, the information was taken from next willing mother.

Data were analyzed using Statistical Package for the Social Sciences (SPSS) software version 20.0 and appropriate statistical tests were used accordingly.

\section{RESULTS}

A total of 120 children of age group between 0 and 14 years were surveyed. Table 1 shows the distribution of subjects according to their age and sex. Majority of them were in the age group of $1-5$ years $59(49.2 \%)$, of male sex 61 (50.8\%), Hindu 98 (81.7\%) belonging to joint family $86(71.7 \%)$ and socio-economic class upper lower 49 (40.8\%). Regarding mothers of the children, majority were in the age group 20-29 years 81 (67.5\%). About $46(38.3 \%)$ of the mothers completed their education till middle class, 75 (62.5\%) got married at age 16-19 years and 101 (84.2\%) were unemployed.

\begin{tabular}{|c|c|c|c|}
\hline Age & Male $\boldsymbol{N}(\%)$ & Female $\boldsymbol{N}(\%)$ & Total $N$ \\
\hline Infants (0-12 months) & $16(44.4)$ & $20(55.6)$ & 36 \\
\hline $1-5$ years & $33(55.9)$ & $26(44.1)$ & 59 \\
\hline \multirow[t]{2}{*}{$5-14$ years } & $12(48)$ & $13(52)$ & 25 \\
\hline & $61(50.8)$ & $59(49.2)$ & 120 \\
\hline
\end{tabular}

$n=$ Total number of children, $N=$ Number of children in respective columns 
Among the children, $97(80.8 \%)$ were delivered through normal vaginal delivery, $63(52.5 \%)$ had a normal birth weight, $57(47.5 \%)$ had low birth weight and $98(81.7 \%)$ were first order babies. Only 30 $(25 \%)$ of the children in the study population were benefited from the nearby Integrated Child Development Services (ICDS) centers. Among the rest of the children not benefited from ICDS centers, $55(61.1 \%)$ of their mothers had no knowledge about ICDS centers and their services. Among the study population, the percentage of children having common illness for the past 2 weeks from the day of the visit were as follows: Diarrhea 19 (15.8\%), acute respiratory tract infections (ARI) 21 (17.5\%), worm expulsion 16 (13.3\%), skin diseases $24(20 \%)$ and pallor $21(17.5 \%)$ respectively.

Table 2 shows that among the infants, $9(25 \%)$ were underweight, $3(8.3 \%)$ were stunted, $22(61.1 \%)$ were wasted and $23(63.9 \%)$ showed thinness. Among 1-5 years aged children 18 (30.5\%) were underweight, 17 (28.8\%) were stunted, 17 (28.8\%) were wasted, 12 (20.3\%) had MUAC $12.5-13.5 \mathrm{~cm}$ and 17 (28.8\%) showed thinness. Among 5-14 years aged children 11 (44\%) were underweight, 10 $(40 \%)$ were stunted and $12(48 \%)$ showed thinness.

A child is diagnosed with under-nutrition if any one criterion is present: (1) WAZ $<2$ (2) HAZ $<2$.

Finally, the prevalence of under-nutrition among the study population came around $54(45 \%)$.

Table 3 shows the association and its strength with the factors, which were significantly associated with under-nutrition. Bivariate analysis shows that the factors such as age of child, improper complementary feeding, low socio-economic class, normal delivery, weight of the baby, birth order of the baby, lack of usage of ICDS services in the slum and presence of any of the common illness (ARI, diarrhea, worm expulsions, pallor, skin diseases) for past 2 weeks in the child were significantly associated with increased risk of under-nutrition.

Variables such as sex, religion, occupation of mother, mother's age at marriage, education and occupation of father, type of family, practice of prelacteal feeding, exclusive breast feeding, overcrowding, type of house, type of latrine, smoke nuisance were not significantly associated with under-nutrition in bivariate analysis (data not shown). The variables already found significant in bivariate analysis were entered into a multiple logistic model (binary logistic: Link function = Log it), by "Enter" method.

When controlling for the other variables, type of delivery lost its significance. However other variables such as age of the child,

\begin{tabular}{|c|c|c|c|c|}
\hline Criteria & $\begin{array}{l}\text { Infants } \\
N(\%)\end{array}$ & $\begin{array}{c}1-5 \text { years } \\
N(\%)\end{array}$ & $\begin{array}{c}5-14 \text { years } N \\
(\%)\end{array}$ & $\begin{array}{l}\text { Total } \\
N(\%)\end{array}$ \\
\hline W/A & $9(25)$ & $18(30.5)$ & $11(44)$ & $38(31.7)$ \\
\hline $\mathrm{H} / \mathrm{A}$ & $3(8.3)$ & $17(28.8)$ & $10(40)$ & $30(25)$ \\
\hline $\mathrm{BMI} / \mathrm{A}$ & $23(63.9)$ & $17(28.8)$ & $12(48)$ & $52(43.3)$ \\
\hline W/H & $22(61.1)$ & $17(28.8)$ & - & 39 (41.05) \\
\hline MUAC & - & $12(20.3)$ & - & $12(20.3)$ \\
\hline
\end{tabular}

$n=$ Total number of children, $N=$ Number of children in respective columns, W/A = Weight for age, $\mathrm{H} / \mathrm{A}=$ Height for age, $\mathrm{BMI} / \mathrm{A}=$ Body mass index for age, $\mathrm{W} / \mathrm{H}=$ Weight for height, MUAC = Mid upper arm circumference. Dotted line denotes the criteria not applicable for the age group

\begin{tabular}{|c|c|c|c|}
\hline Independent variable & Under-nutrition present $\mathbf{N}(\%)$ & OR $(95 \% \mathrm{Cl})$ & AOR $(95 \% \mathrm{Cl})$ \\
\hline Age of child (continuous variable) & - & $1.019(1.008-1.030)$ & $1.015(1-1.031)^{*}$ \\
\hline \multicolumn{4}{|l|}{ Socioeconomic status } \\
\hline Lower middle and below (97) & $48(49.5)$ & $2.776(1.009-7.638)$ & $6.065(1.413-26.03)^{*}$ \\
\hline Upper middle and above (Ref) (23) & $6(26.1)$ & & \\
\hline \multicolumn{4}{|l|}{ Birth order } \\
\hline $1^{\text {st }}(98)$ & $49(50)$ & $3.400(1.163-9.941)$ & $5.075(1.376-18.71)^{*}$ \\
\hline $2^{\text {nd }}$ and above (Ref) (22) & $5(22.7)$ & & \\
\hline \multicolumn{4}{|l|}{ Birth weight } \\
\hline$<2.5 \mathrm{~kg}(57)$ & $33(57.9)$ & $2.75(1.309-5.777)$ & $2.97(1.06-8.28)^{*}$ \\
\hline$\geq 2.5 \mathrm{~kg}$ (Ref) (63) & $21(33.3)$ & & \\
\hline \multicolumn{4}{|l|}{ Type of delivery } \\
\hline Normal (97) & $49(50.5)$ & $3.675(1.263-10.7)$ & $2.413(0.63-9.312)$ \\
\hline Cesarean (Ref) (23) & $5(21.7)$ & & \\
\hline \multicolumn{4}{|l|}{ Complementary feeding } \\
\hline Improper (65) & $38(58.4)$ & $3.431(1.60-7.35)$ & $4.47(1.47-12.69)^{*}$ \\
\hline Proper (Ref) (55) & $16(29.1)$ & & \\
\hline \multicolumn{4}{|l|}{ ICDS usage } \\
\hline No (90) & $46(51.1)$ & $2.875(1.159-7.133)$ & $3.775(1.05-13.527)^{*}$ \\
\hline Yes (Ref) (30) & $8(26.7)$ & & \\
\hline \multicolumn{4}{|l|}{ Illness (past 2 weeks) } \\
\hline Yes (57) & $36(63.1)$ & $4.28(1.99-9.23)$ & $6.8(2.43-19.06)^{*}$ \\
\hline No (63) & $18(28.6)$ & & \\
\hline
\end{tabular}

$N=$ Total number of children in each group, OR = Odds ratio, AOR = Adjusted odds ratio, $\mathrm{Cl}=$ Confidence interval, ICDS = Integrated Child Development Services. *Significant in multivariate analysis 
socio-economic class, birth weight, birth order, improper complimentary feeding and presence of illness and use of ICDS services by mother stayed significantly associated in the multivariate analysis.

\section{DISCUSSION}

Beginning with the positive aspects found in the study were that all the children of the study population in the slum of Chetla were born in Institutions either private or government hospitals and also they were completely immunized until date, but the prevalence of under-nutrition is still higher $54(45 \%)$. About $38(31.7 \%)$ of the study population were underweight, $30(25 \%)$ were stunted, $52(43.3 \%)$ showed thinness overall in children from birth to 14 years of age. About $39(41.05 \%)$ in the under-five population showed wasting. When comparing with the NFHS-3, West Bengal data, ${ }^{[5]}$ underweight and wasting are slightly lower in the study population than in the state where figures were $38.7 \%$ and $44.6 \%$ respectively, but wasting was higher $41 \%$ than that of $17 \%$ in the state. The prevalence of ARI and diarrhea was also high $17 \%$ and $16 \%$ than that of $13 \%$ and $15 \%$ in the state respectively.

Under-nutrition was more or less equal between males (50.8\%) and females $(49.2 \%)$ in the present study. In a study ${ }^{\left[{ }^{[0]}\right.}$ conducted in the tribal community of West Bengal, prevalence of malnutrition was $50.67 \%$ among infants and it also increased with increasing age and it was significantly more among infants $>6$ months of age than infants of $<6$ months whereas in Chetla slum infants $25 \%$ were underweight. In the present study, it was found that the mothers in the slum of Chetla were mostly unaware of the importance of ICDS centers and their services. About 90 (75\%) of mothers did not make use of ICDS centers nearby their residences among which 55 (61\%) did not have any knowledge regarding services provided in those centers. This might be an important reason for the under-nutrition of their children which was also statistically proved in the study.

\section{CONCLUSION}

The present study was probably the first of its kind in Kolkata, to assess the nutritional status amongst the children aged from 0 to 14 years of age using the WHO Child Growth Standards. It is difficult to compare the different age group of children as a whole which might be the limitation of the study but the use of WHO Anthro and Anthro Plus software, for the assessment of the underweight, stunting and wasting and thinness among study population is an advantage in deriving those criteria. The nutritional status of children in the slum of Chetla was not satisfactory despite proper immunization coverage and institutional deliveries. Malnutrition is still a major health problem in India, with no disparity between urban slum and rural area. In spite of National Health Policy-2002, various health programs and schemes, the awareness of mother about health is kept at a very low level. Every endeavor should be made to combat this problem of malnutrition with multipronged approach such as nutritional supplementation, growth monitoring, health education, safe delivery practices, safe newborn care, giving importance to women education and last but not the least nutritional education.

\section{REFERENCES}

1. web.worldbank.org. Washington: The World Bank; c2013. Available from: http://www.web.worldbank.org/wbsite/external/countries/southa siaext/0, contentmdk:20916955 pagepk:146736 pipk:146830 thesite pk:223547,00.html. [Last updated on 2012 Jan 31; Last cited on 2012 Mar 16].

2. www.unicef.org. India: United Nations Children's Fund. Available from: http://www.unicef.org/india/children_2356.htm. [Last updated on 2003 Jun 11; Last cited on 2012 Mar 12].

3. www.unscn.org. Geneva: $5^{\text {th }}$ Report on the World Nutrition Situation: Nutrition for Improved Development Outcomes — March 2004. Available from: http://www.unscn.org/layout/modules/resources/files/rwns5.pdf. [Last cited on 2012 Mar 18].

4. Smith LC, Ruel MT, Ndiaye A. Why is child malnutrition lower in urban than in rural areas? Evidence from 36 developing countries. World Dev 2005;33:1285-05.

5. International Institute for Population Sciences (IIPS) and Macro International. National Family Health Survey (NFHS-3), 2005-06: India. Vol. I. Mumbai: IIPS; 2007.

6. Mitra SP. A study of dietary intake and nutritional status of under five children in slums of Kolkata city. Indian J Community Med 2007;32:92.

7. www.who.int. Geneva: World Health Organization; c2013 Available from: http://www.who.int/childgrowth/software/en/. [Last updated on 2011 Jan 19; Last cited on 2012 Mar 16].

8. www.who.int. Geneva: World Health Organization; c2013. Available from: http://www.who.int/growthref/tools/en/. [Last updated on 2011 Jan 19; Last cited on 2012 Mar 16].

9. Banerjee B, Mandal ON. An intervention study in malnutrition among infants in a tribal community of West Bengal. Indian J Community Med 2005;30:27.

10. Mittal A, Singh J, Ahluwalia SK. Effect of maternal factors on nutritional status of 1-5 years old children in urban slum population. Indian J Community Med 2007;32:264-7.

11. Choudhary S, Mishra CP, Shukla KP. Nutritional status of adolescent girls in rural area of Varanasi. Indian J Prev Soc Med 2003;34:1-2.

12. Roy S, Dasgupta A, Pal B. Feeding practices of children in an urban slum of Kolkata. Indian J Community Med 2009;34:362-3.

13. Dasgupta A, Butt A, Saha TK, Basu G, Chattopadhyay A, Mukherjee A. Assessment of malnutrition among adolescents: Can BMI be replaced by MUAC. Indian J Community Med 2010;35:276-9.

14. Seetharaman N, Chacko TV, Shankar S, Mathew AC. Measuring malnutrition-The role of $Z$ scores and the composite index of anthropometric failure (CIAF). Indian J Community Med 2007;32:35-9.

15. Brahmam S. National nutrition monitoring bureau in India - An overview. Indian J Community Med 2007;32:7-9.

16. Ghai OP, Gupta P, Paul VK. Ghai essential pediatrics, adolescent health and development. Pediatrics 2006;6:66.

17. Chatterjee S, Saha S. A study on knowledge and practice of mothers regarding infant feeding and nutritional status of under-five children attending immunization clinic of a medical college. Internet $\mathrm{J}$ Nutr Wellness 2008;5:1.

18. Rao VG, Sugunan AP, Murhekar MV, Sehgal SC. Malnutrition and high childhood mortality among the onge tribe of the Andaman and Nicobar Islands. Public Health Nutr 2006;9:19-25.

19. Biswas S, Bose K, Mukhopadhyay A, Bhadra M. Mid-upper arm circumference based undernutrition among Bengalee children of Chapra, West Bengal, India. Iran J Pediatr 2010;20:63-8.

20. Joseph B, Rebello A, Kullu P, Raj VD. Prevalence of malnutrition in rural Karnataka, South India: A comparison of anthropometric indicators. J Health Popul Nutr 2002;20:239-44.

How to cite this article: Mandal S, Prabhakar VR, Pal J, Parthasarathi R, Biswas R. An assessment of nutritional status of children aged 0-14 years in a slum area of Kolkata. Int J Med Public Health 2014;4:159-62.

Source of Support: Nil, Conflict of Interest: None declared. 